\title{
Architecture without Man: New Development Scenarios of Infrastructure and Innovation in Trieste
}

\begin{abstract}
By Thomas Bisiani ${ }^{*}$
The study investigates the possibility of developing infrastructure in Trieste, as a larger system, on an international scale: The Belt and Road Initiative. The consequences of this development, in a city rich of research facilities and innovation centers, are innovative and propose new questions on the evolution of architecture and of landscapes linked to logistics and infrastructure and on the material and spatial consequences of digitalization. The research defines a set of specific possible project proposals, compatible or alternative to one another, but that once analyzed, they all underline how mankind seems progressively emarginated from these places. The architecture of the physical and immaterial infrastructures begins to light a new question, how its nature can appear both, anthropic and unrecognizably alien. It is about elements that are creating a real ecosystem at the global scale, essential to the maintenance of our way of life, but with respect to which we have become strangers.
\end{abstract}

\section{Introduction}

July $16^{\text {th }}, 1945$ at 5:29 A.M. in the Nevada Desert, the first nuclear explosion in history takes place. This is also the conventional starting date for the new geologic era called Anthropocene. This term is used in order to indicate how men and his activities are the main causes of territorial, structural and climatic changes of the planet. ${ }^{1}$

From this point of view, our planet is better represented by transport and energy infrastructure and by means of communication between its inhabitants and the resources of the earth.

Connectivity $^{2}$ has substituted division as the new paradigm of global organization. The infrastructure network is better at describing how the world functions rather than the political maps with its state borders.

Today the map of the world needs to represent the single cities, the means of communication, the pipelines and the energy supply network, the wirings and the other elements of the global civilization networks.

One of the consequences of this model is the continuous competition status between those cities that wish to obtain the maximum advantage from the added value reachable from their position in relation to the financial, technological, knowledge and talent fluxes that pass through these organisms.

\footnotetext{
*Adjunct Professor, University of Trieste, Italy.

1. M. Carta, Re_Cyclical Urbanism. Visioni, Paradigmi e Progetti per la Metamorfosi Circolare (Trento: Listlab, 2016).

2. P. Khanna, Connectography. Mapping the Future of Global Civilization (New York: Random House, 2016).
} 
It is clear that connectivity is one of the main drivers of the transition toward more global, complex and less foreseeable economic systems.

The scenarios that work, are not pre-dictated but rather describe processes: the greater the projection divergence, the more the scenario system that results becomes rich. In an era where the future appears very unsure, the elaboration of accurate future visions is not so much a matter of univocal and alternative choices, but of developing interconnections between the available alternative visions. ${ }^{3}$

From the point of view of connectivity, the current system that attracts the biggest international investments is the BRI (Belt and Road Initiative), a series of infrastructural projects by land and sea, primarily promoted by China, that have the objective that aim at reinforcing the commercial relationship between Europe and Asia.

In this scenario the port of Trieste, positioned at the northern edge of the Mediterranean Sea, constitutes an important access point into Europe for fluxes arriving through the Suez Canal (Figure 1). From the strategic point of view, this role is reinforced by the proximity to the Piraeus, whose port authority is controlled mainly by the Chinese. Trieste is also closer to Bavaria, one of Europe's locomotives, than the German port of Hamburg. In addition, it disposes of significant railway connections with Duisburg, one of the major logistics platforms integrated with the ports of North Europe and Budapest, one of the privileged access points of the European railway system coming from Asia. ${ }^{4}$

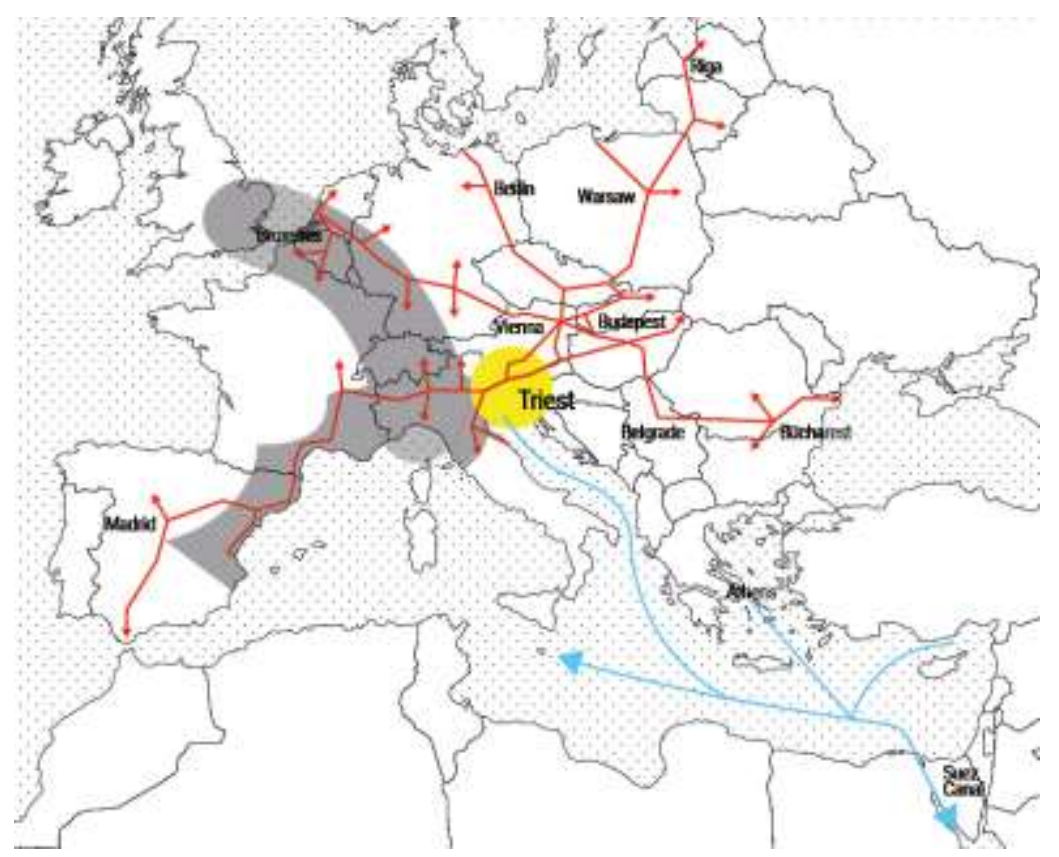

Figure 1. Framing at the Continental Scale, Pointing out the European Macro Systems Blue Banana and Arco Latino (Latin Arch) and the Intermodal Node of Trieste (in Yellow), Meeting Point of the Sea Routes and the European Corridors Source: Elaboration by Matteo Savron.

3. C. Ratti and M. Claudel, La città di domani. Come le Reti Stanno Cambiando il Futuro Urbano (Torino: Einaudi, 2017.

4. S. Paffumi, "Il Secolo Asiatico e la Nuova via della Seta," Icon 54 (2019): 52-56. 
The geography of the planet is not, however, only redesigned by infrastructural networks. The so called IV industrial revolution, that we are experiencing, is characterized by the use of Big Data as a new raw material and by the ease by which it is possible to develop new software. It is, nevertheless, a dimension only apparently intangible, the ethereal metaphor of the cloud, for the management and the elaboration of data from remote. It is in complete contradiction with the physical realities of the extractions of minerals necessary for the realization of all the digital devices that are part of our daily lives.

The derived schemes are chain rings that link the exploitation of the natural resources, the usage of manual labor and the elaboration of data through detection, logistic and algorithmic networks. The scale of this system, because of its complexity, is almost beyond imagining, so much so that the Dell computer company has declared to not be able to retrace the steps of its metal and rare land supplies necessary for the realization of its products, all the way to the source. ${ }^{5}$

The so-called smartphone landscapes are new panoramas that man is creating. An example can be found in Indonesia, where 30\% of the tin used for the welding of all electric products of the world comes from. On the island of Bangka, vast areas are being deforested and dredged in order to make space for basins for the collection of process water. The extraction activity linked to the technologic electric chain, besides from being one of the causes of land consumption, is intrinsically unsustainable, as it regards the extraction of resources, that are by definition, limited.

Three cases linked to the port system of Trieste demonstrate how an ecosystem made of infrastructure and innovation can generate both conditions of development and crisis situations. As a consequence, it can't simply exist as it needs to be designed and managed:

\section{Saipem}

Leader in the energy and infrastructure sector, has placed in Trieste its hub for Submarine Robotics, where OIE (Offset Installation Equipment) is based and has been constructed. This is the most recent and highest technology in the world for the prevention of environmental disasters from underwater oil spills.

\section{Java Biocolloid}

Indonesian industry among the main manufacturers of red algae extracts for the food and pharmaceutical industries. It has established its European headquarters in Trieste, a location that favors the European, Middle Eastern and American distributions along with offering the opportunity to research and develop with the scientific organizations of the territory.

5. F. Cairncross, The Death of Distance. How the Communications Revolution will Change our Lives (Cambridge: Harvard Business Press, 1997). 


\section{The Coltan}

The so called "blue gold" is a superconductor with great ability to store electric charges. In March 2019 a five ton container has been confiscated in the port of Trieste as it violated the laws regarding the handling of radioactive materials. The coltan should have been shaped and transformed in Trieste for the production of microchip and exported.

These examples confirm the existence of a model that rewards the provision of infrastructure and the commitment to innovation, bringing to light, however, criticalities linked to opaque traffics and to the exploitation of rare lands and limited resources of the planet.

Starting from such bases, this study wants to highlight regeneration scenarios of port areas that see Trieste as an incubator of innovation. The objective is to define a landscape of activities of high added value, able to influence the quality of life and job opportunities, exploiting its position as a new port epicenter.

From this point of view, the case of Trieste should not be interpreted as a unique and exceptional emerging phenomenon, but rather as a possible example that, besides its specificities, can help to define a development model of European cities of medium size.

\section{Literature Review}

The design process involving scenarios has been applied in Italy since the post-war period in the planning sector. Starting from the early 2000 these concepts have been represented and analyzed in greater depth subsequently putting them in relation to the use of new instruments and digital methodologies.

This methodology has been developed in Italy in the 50's by Giovanni Astengo, but it can also be found in later examples of application, in Europe, that develop the construction technique of the "previsione" (prevision), borrowing methodologies from the gaming simulation methods for war videogames or from meteorology; all areas that today refer to constantly more powerful calculation instruments. ${ }^{6}$

Astengo's proposed work plan provides a preliminary study for which big possible and alternative hypothesis are formulated in a schematic way, in order to compare them, and possibly subsequently reduce them, in order to extract a single final model.

We are dealing with a methodology that is in contraposition with the revision interpreted in the classic way; that is an extrapolation of a series of trends derived from historical facts ${ }^{7}$ from which an image of the future is created.

6. G. Fraziano, T. Bisiani, L. Di Dato, C. Meninno, A. Venudo and M. Verri, Le Regole del Gioco. Scenari Architettonici e Infrastrutturali per l'Aeroporto FVG (Trieste: EUT Edizioni Università d Trieste, 2015).

7. M. Ferrari, "Reti e Nodi Contemporanei, le Architetture delle Infrastrutture," in L'Architettura del Mondo. Infrastrutture, Mobilità, Nuovi Paesaggi (ed.) A. Ferlenga, M. Biraghi and B. Albrecht. Bologna: Editrice Compositori, 2012. 
Later in the 2000's, during the Urbanism PhD of the IUAV, led by Bernardo Secchi, numerous developments have been further advanced on the subject.

According to Secchi, ${ }^{8}$ the transformation phenomena of the cities are overdetermined, that is, they depend on multiple factors simultaneously; this multiplicity of causes determines a complex model, and as a consequence, its interpretation becomes difficult.

The scenario becomes an instrument to deal with this complexity, isolating some specific aspects and asking the question "What could happen if...". By imagining the development of these phenomena until their extreme or most plausible consequences, images of the future are obtained. Such images can be incoherent or in competition with one another, as well as they can be in antagonism with the subjects that support them. In this case it does not present itself as a methodologic limitation but rather as a series of possibilities among which to choose or mediate in order to find in between solutions.

It is about a critical design that generates alternative choices and that is able to help construct compasses in order to navigate, rather than create preconstructed maps. ${ }^{9}$ This is why the scenarios are able to balance the provocations as they hold a strong bond with reality, they also have hypothetical value and for this reason it is irrelevant if they concretely do not become reality.

In astronomical terms the universe of possible worlds is in continuous expansion and is diversified, ${ }^{10}$ an experimental laboratory where the scenarios are tested, their propagation contributes to the acceleration of the design evolution through selection and mutation of new ideas.

The complexity of the urban phenomena has introduced the development of methodologies with descriptive nature. This effort results necessary in order to analyze the complexity of the urban model described by Secchi through the collaboration of other disciplinary fields and study areas not always usual.

In the past, such condition of complexity could have been caused by the very same analysis methodologies, that in their heterogeneity have described the urban phenomena as a vast trends mosaic, overabundant for describing the past and for defining the future.

Subsequently, the increasingly more pervasive use of digital technologies, both in daily life and in analysis techniques, has allowed to describe this complexity in new and more convincing ways.

Carlo Ratti in 2006 presents Real Time Rome, where the mapping of the usage of cellphones of the people allows to comprehend the urban processes in a dynamic prospective, through the live visualization of the fluxes in relation to the physical elements of the cities, proposing the basis for a real time iteration between the citizens and the urban services.

It is a typical application of the IOT (Internet of things) concept, that at the time could only be based on the evolution speed of the interaction between the

8. B. Secchi, Diario 06. Scenari (Planum, 2002).

9. A. Dunne and F. Raby, Speculative Everything. Design, Fiction, and Social Dreaming (Cambridge: MIT Press, 2013).

10. L. Dolezel, Heterocosmica. Fiction and Possible Words (Baltimore: Johns Hopkins University Press, 1998). 
system of users and of the providers of services according to Bottom/ $\mathrm{Up}$ and Top/Down logics, which have proven to be too slow.

Today through the capture of Big Data and its analysis with applications of Artificial Intelligence it is possible to separately collect and later aggregate large quantities of data. This allows to create more efficient digital twins, more or less complex and specific for what the study or analysis requires, allowing in the end, the systematic construction of scenarios by using techniques of digital simulations.

Carta ${ }^{11}$ has theorized, with the manifest of the "Città Aumentata" (augmented city), a "stationary" model where a large quantity of sources, like technologic, biologic and human sensors, concur to define a cognitive framework that is capable of constructing collaborative scenarios that are able to modify themselves promptly where the data and the convergence of the fluxes represent the added value.

The immaterial dimension of the city is born with the concept of the global village, ${ }^{12}$ way before the birth of the internet. Starting from the 80 's, the so-called network society ${ }^{13}$ and its reference context will be constructed: the space of the fluxes where the physical and the digital space mix.

The more radical hypothesis, linked to the post-information era and the socalled death of the distance ${ }^{14}$ that had implied the crises of urban models, in reality, did not happen.

This means that the data landscape is not autonomous, a natural convergence between the bit in the net and the atoms in the cities is, in fact, happening.

In the last twenty years the cities have grown like never before, the majority of the human population lives in the cities, the urban life has become new normality. ${ }^{15}$

The cities, besides consuming the most part of our energy resources and being the principal cause of carbon monoxide emissions in the atmosphere, are also the centers of innovation and wealth that derives from the added value of the financial, technologic, knowledge and talent fluxes that pass through them.

The city then, is the solution, not the problem. New models have been emerging, such as the endless city, ${ }^{16}$ the city of 40, 50, 100 million inhabitants in Asia and America. These cities arise in correspondence of the big communications and logistic spines and design new geopolitics, able to be more influential than entire nations.

Europe follows this tendency but with different growth rates and different models. According to ONU, 77\% of European cities with more than 300,000

11. M. Carta, Augmented City. A Paradigm Shift (Trento: Listlab, 2017).

12. M. McLuhan and G. E. Stearn (eds.), McLuhan. Hot and Cool. A Primer for the Understanding of and a Critical Symposium with Responses by McLuhan (New York: Dial Press, 1967).

13. M. Castell, The Rise of the Network Society (Cambridge: Blackwell, 1996).

14. Cairncross, The Death of Distance. How the Communications Revolution will Change our Lives, 1997.

15. R. Burdett and P. Rode, Shaping City (London: Phaidon Press, 2018).

16. R. Burdett and D. Sudjic, Living in the Endless City (London: Phaidon Press, 2011). 
habitants have experienced a growth in population and the 2030 prevision foresees this number to reach $96 \% .^{17}$

This is not an absolute tendency, there is a lot of competition between cities, and a selection between those that are able to offer better life quality and job opportunities is taking place. For this reason they are an attraction for the population and the younger generations, the others are destined to lose weight and importance. The cities emerging from this Darwinian arena are those who in the last few years have been able to program their future, constructing visions projected to $15,20,30$ years and by placing mankind at the center of their programs.

In order to erect valuable scenarios it is important to keep the parameters that have been identified in mind, the trend and growth of the cities, the strategic meaning of the infrastructure and of the data, and the presence of the immaterial innovation factors in the physical context of the cities.

\section{Methodology}

The information derived from the past (our previous experiences, history), today is not sufficient to make the right decisions anymore.

For this reason, it is possible to resort to the methodology of the scenarios, as a simulation instrument, prevision and pre evaluation of great transformations, and in general as an instrument propaedeutic to design on different scales.

In this specific case, as shown by the entity of the affected areas, the proximity to the different administrative environments (Comune di Trieste, Comune di Muggia, Port of Trieste), the economic aspects (existing, in the course of developing and reconverted production areas), the social (the realization of new job opportunities and the increase in population) and political implications (strategic role of the Port of Trieste on a national and international scale), and the numerous public and private entities involved in the development of the areas under transformation are individuated. Through the scenarios some "metaprojects" have been defined in order to:

1. construct the main themes of the planning of the areas and of the single projects;

2. develop settlement principles and parameters of general dimensioning for the identified areas.

These metaprojects could become the guidelines for the design of the areas, and for this reason a second phase of more in depth study has been implemented and composed of:

1. the individualization, from a multitude of strategic places, of a specific area for the transformation;

17. L. Bellicini and F. Toso, Un Nuovo Paradigma Urbano: "La Città è la Soluzione non il Problema," CRESME. Il Mercato delle Costruzioni (2018): 8 - 13-8 - 14. 
2. the construction of a platform (data, designated use, layout) of feasible development hypothesis.

The scenarios are not projects but simulations, "guided simplifications" of the problem, with evolutive and complementary characteristics, that allow to visualize the potentials and criticalities of the transformation of the areas and their evaluation under different aspects.

As simulations, the scenario is based on two design principles, one objective and analytic, formed on a collection of data and analysis, and the other dependent on interpretation, assessment and evaluation of the design proposals as a whole.

In order to answer the question "what would happen if...?" three main indicators have been picked out as the principal ones that construct, along with normal sizing criteria, more general topics that are able to place the areas along with a strategic vision of a larger zone (the port system of the eastern Adriatic Sea) (Figures 2-3):

1. infrastructure system;

2. plates and commercial and productive districts;

3. logistics networks.

The infrastructure system raises questions on the general mobility, on the organization of the accessibility to the areas and on the possibility to accept new uses and activities.

The plates and commercial and productive districts constitute the analysis of the economic-political situation, of the investment strategies and of the specific initiatives of the single operators.

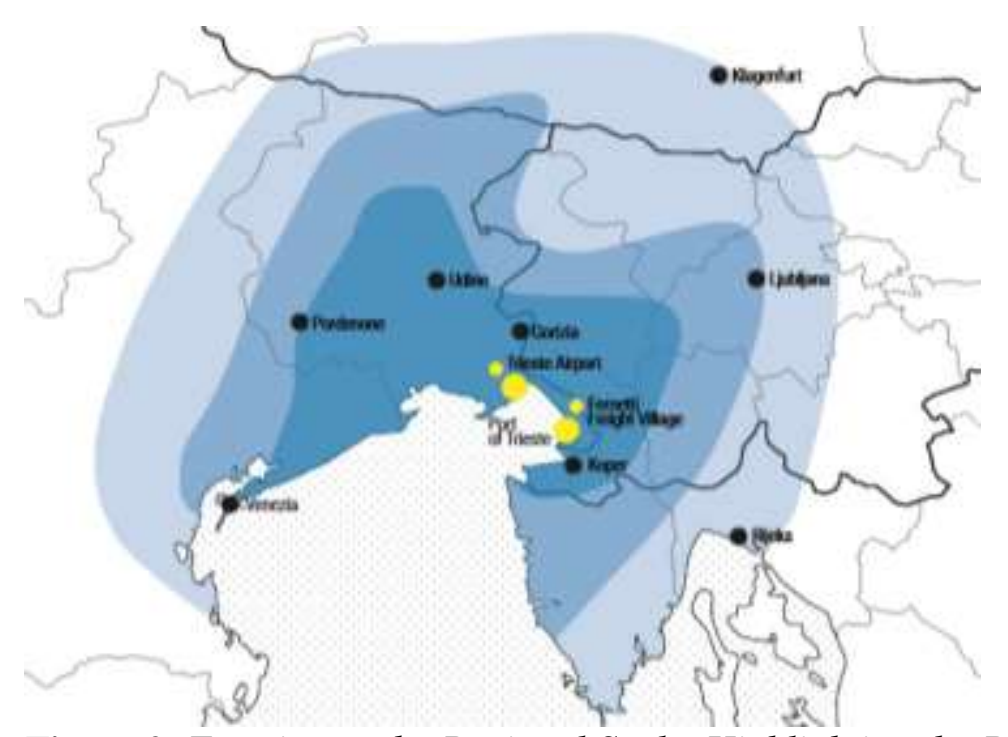

Figure 2. Framing at the Regional Scale, Highlighting the Ports System of Trieste and Monfalcone, of the Fernetti Freight Village and the Trieste Airport (in Yellow) and Individualization of the Isochronous with Origin in the Intermodal Hub of Ronchi dei Legionari (60, 90, 120 Minutes)

Source: Elaboration by Matteo Savron. 
Logistics and degree of multimodality are key indicators, characteristic of the state of the affairs of the sites that are being evaluated which connotes its functional vocation.

Based on these indicators, characteristics and extent of the areas have been assessed and system variables and constant elements have been defined and have become the structural elements of the layout and of the main transformation choices developed on the project level.

From the methodological point of view, the study is developed as a natural successor to the previous research carried out with the University of Trieste, for the definition of the guidelines for the realization of the intermodal hub of Trieste Airport.

The project, elaborated by the research group of the University of Trieste, has received the GlobalAirRail Awards 2015 within the category "Travelport Project of the Year"; has received an honorable mention for the research activities of The Plan Best Paper $2015^{18}$ and won for the research activities of the Propeller Club Port of Monfalcone.

Contrary to previous studies, that for thirty years have developed oversized proposals, the methodology of the scenarios has allowed to acquire the guidelines for the design of the intermodal hub of the airport that has later been built in $2018 .^{19}$

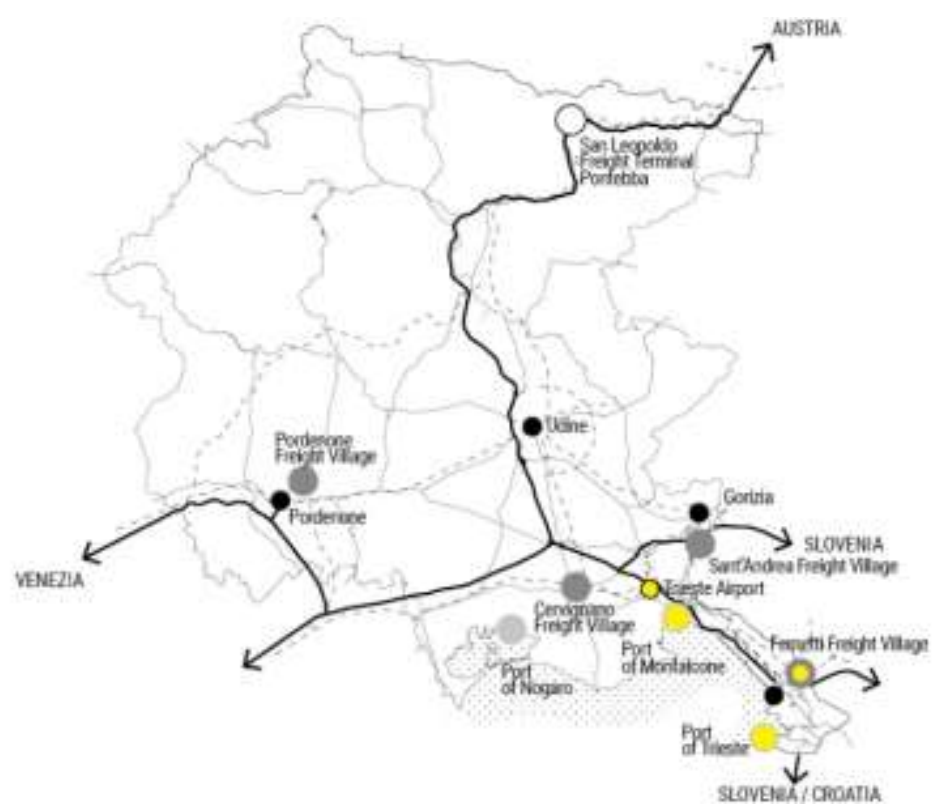

Figure 3. Goods and Passengers Interchange Nodes of the FVG, Particularly the Ports of Trieste and Monfalcone, the Fernetti Freight Village and the Trieste Airport (in Yellow)

Source: Elaboration by Matteo Savron.

18. G. Fraziano, Trieste, la Misura del Possibile (Trieste: Fresco Editore, 2014).

19. T. Bisiani, G. Fraziano, C. Meninno and A. Venudo, "Il Nuovo Polo Intermodale del Trieste Airport." Studi Goriziani 113 (2020): 113-129. 
For the airport, three development scenarios had been identified, one alternative to the other, in order to evaluate the advantages and disadvantages and to define the suitability compared to the contextual conditions.

This approach has allowed to modulate by three degrees -one per scenario- a variable considered strategic in the case of the Trieste Airport, the level of infrastructural services.

The development activity of the scenarios was carried out on many scales and dealing with different disciplinary fields (planning, architecture, infrastructure). This multidisciplinary approach to the project has become necessary in order to ensure a solution able to guarantee the integration and interoperability of the single components of the new hub. Particularly the degree of detail obtained by the different architectonic and infrastructural scales has allowed the verification of the choices made in relation to the economic limitations of the Airport.

Thus it was possible to choose the optimal design solution in order to enhance the investment in relation to the functional program. The work, realized in 13 months, is currently at its second year of operation.

The second part of the research activity has applied the same methodology to the areas adjacent to the intermodal hub in order to define their future development.

In this case the hub was considered a constant in all three scenarios and different hypothesis of schemes, and intensity of use has been evaluated, in order to verify the minimal, optimal and crisis condition of the system.

The possible alternatives developed will allow the Administrations to knowingly choose one of the possibilities individuated or to rearrange them in a new complex framework.

The results of the activities, developed as an applied research, have permitted to elaborate the preliminary project for the new hub and the guidelines for the urban planning of the surrounding areas.

The development activities of the research have been articulated in operative phases that have involved different interdisciplinary skills:

- Identification of the demand for the projection and simplification of the problem: "what would happen if..."

- Identification of the goals and of the strategy: general picture of the hypothesis on the bases of data

- List of actors and of the entities involved

- Pre dimensioning of spaces, functions and definition of the layout, organization of data

- Definition of settlement rules and general parameters

- Development of the stages and timing (short, medium, long periods of time)

- Visualization of the places and the assumed transformations (visioning)

- Evaluation of the transformations and of the territorial implications (matrices)

- Synthesis of the results: system variables and invariant 
In conclusion, the objective is to develop the scenarios, as they are simulations, not to correct the present nor to predict the future, but to positively influence it by exploring and comparing alternative possibilities.

Through the use of the scenarios and their comparison, it becomes easier to arise and underline the innovative elements that can, according to an evolutive logic, accelerate change.

\section{Results}

The first result obtained was the individuation of four strategic areas. Starting from the three significant indicators (infrastructure, plates and commercial and productive districts, logistics networks), the initiatives and the visions for both institutional actors (Comune di Trieste, Mare Adriatico Orientale Port Authority, University of Trieste, Area Science Park) and of stakeholders and private subjects, have been defined through interviews. The questions were about four strategic areas: the railway station of Prosecco, the Porto Vecchio, Campo Marzio area, and the Canale navigabile (Figure 4).

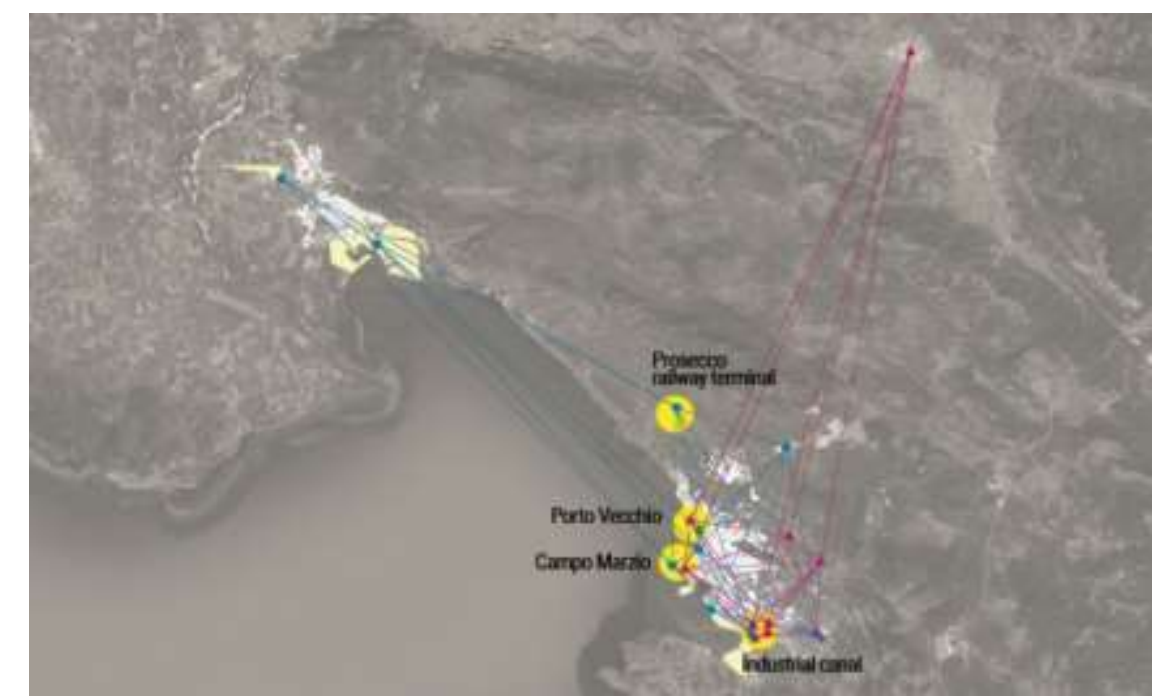

Figure 4. Individuation of the Four Development Areas (in Yellow) and of the Two Macro Systems of the Infrastructural Services (in cyan) and of innovation (in magenta), comprised of Highly Innovative Activities

Source: Elaboration by Matteo Savron.

\section{Prosecco Railway Station}

This is a retroportuale area with a railway yard, inside an industrial context of production and sale. The railway line, currently disused, can directly connect Trieste to Vienna, the production reality of the neighboring areas could deduce significant advantages from the reactivation of the railway, simplifying the transport of the incoming raw materials and of the outgoing products. 


\section{Porto Vecchio}

The port area designed by the Habsburg between the end of the 800's and the beginning of the 900's is a great strategic interest for the city, as it is located in continuation with the urban fabric of the historic center.

Some of the characters of this area, in part already subject to transformations, include, docks with particularly deep backdrops and the presence of important realities for the research and development sector, such as the underwater robotics of Saipem and the headquarters of Euro Science Open Forum of 2020. The central station of the city is located nearby, and it amplifies the intermodal value of the space.

\section{Campo Marzio}

Located at the opposite extremity of Porto Vecchio, in continuity with the urban center and near the main entrance of Porto Nuovo, this area also offers the possibility to reactivate the second railway station at the head of the city. Logistics activities (steel, rubber and water) and of import-export can enjoy the benefits of the already existing infrastructures that enhance the area. Research and development can be placed in the many disused buildings with urban character present in the area.

\section{Canale Industriale (Industrial Canal)}

The development of this area with a total industrial character has large potentials as it is currently insufficiently valorized. The area is partially characterized as SIN (polluted site of national interest) and its transformation could also offer the possibility of an environmental regeneration. The existing docks already allow the mooring of large cargo ships, and the railway that passes through the surrounding industrial fabric has to be reactivated. Java Biocolloid has already chosen this location to position its European headquarters.

The cross referencing of the data collected during the interviews has permitted the selection, by comparing the strategic areas, of the area subject to a more indepth study, that of the Canale industriale (industrial canal).

The field, where the primal interests of the participating subjects have converged, is composed of the lots of the former Tabacchi manufacturer and of the former Acciaierie Giuliane, along with a logistic area currently in disuse, located at the head of the canal and of the existing docks.

This area holds all the characteristics to reach a high potential of infrastructural development in a relatively short time frame, as it already has docks and a railway stop and is the interest of private industrial investments of innovative character.

The area occupies a strategic position, as it is located at the center of an area that the study has baptized as "logistics triangle," 20 defined by the Porto Nuovo (new port) system, the logistics platform of the Molo VII, the new inland terminal

20. M. Savron, Trieste: Nuovi Scenari per uno Sviluppo tra Infrastruttura e Innovazione. Unpublished Thesis (Trieste: Università degli Studi di Trieste, 2020). 
of Trieste and of the ex-area Aquila, and the future Multipurpose Terminal, recently acquired by Seastock, a public Hungarian company.

For this reason, it is important to underline that the position of Trieste guarantees, on the one hand, shorter travel times of ships coming from the Suez Canal, point of confluence of the eastern routes, and on the other, quick connections on railway tracks in the direction of the major European destinations. Following the individualization of the area, as a consequence, three alternative scenarios have been proposed that are able to answer all the different expectations of the actors interested in the development of the area: the cold chain logistics center, the industrial hub, and the data center (Figure 5).

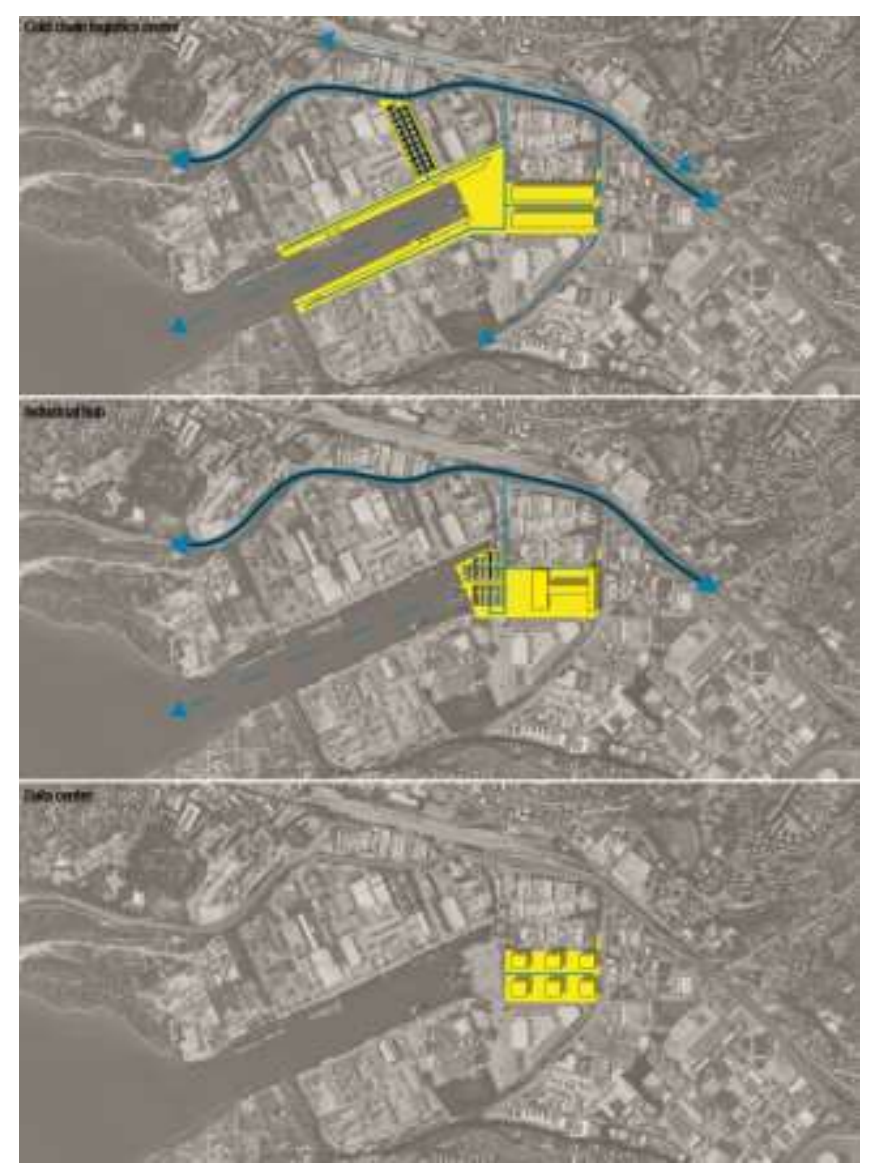

Figure 5. The Three Alternative Development Scenarios Individuated for the Area of the Industrial Canal with the Identification of the Heavy Infrastructures Connected to the Case Study

Source: Elaboration by Matteo Savron.

\section{The Cold Chain Logistics Center}

The conversion of the lot into a logistics area includes the construction of two large mechanized warehouses destined for the storage of goods. The two new buildings are to be placed in parallel with one another, and located longitudinally, between the docks and the railway stop, in order to have large maneuver areas for the loading and unloading activities of goods. 
Moreover, an important multimodal terminal is also included and it is articulated in three parts, at the head of the docks with the owners' headquarters, at the center with truck connections headed to the main arteries of the city all the way to the opposite side and to the railway station.

The ensemble guarantees a perfect reliability and operativity of the system, as well as minimal impact on the maintaining of the ideal environmental conditions along the cold chain for the right condition for the preservation of the handled goods.

\section{The Industrial Hub}

With the goal aiming at enhancing the development activities lined to the Sistema Argo and Freeway Trieste projects, and by utilizing the presence on the territory of Area Science Park, the third park in Italy for the birth and the development of startups, the scenario promotes an Innovation Factory located within the growing industrial fabric.

The structure is destined for the development of innovative products by providing in one place, the technology, the knowledge and the infrastructure in order to allow the designers with original ideas to quickly shift from concept to production. A workspace, but also a research center, that provides expertise on the subject of technology, knowledge and calculated monitoring of the research and development.

The structure is destined for the development of innovative products by providing in one place, the technology, the knowledge and the infrastructure in order to allow the designers with original ideas to quickly shift from concept to production. A workspace, but also a research center, that provides expertise on the subject of technology, knowledge and calculated monitoring of the research and development

\section{Data Center}

In the current geopolitical context, pots have assumed a growing importance as a strategic factor of a country that, through the sea, is projected to the rest of the world. In the eyes of the continuous infrastructural and technologic development, in this scenario the realization of a data center in service to the logistics and the transport systems, both within and outside the boundaries of the Autorità del Sistema Portuale del Mare Adriatico Orientale is proposed, with the objective aimed at digitalizing the port activities more and more and to maintain the terminal at a high competitive level on an international scale. The data center represents the fulcrum of this strategy, as it guarantees the 24/7 operations of all processes, the communications and support services of the logistics activities.

Among these scenarios a forth complex one has been determined, constructed by the union of the first two (industrial hub and logistics center), that has been developed on the design scale, identifying a hybrid solution (Figure 6) in order to offer a wider range of solutions and maximize investments and interests of the involved entities. 

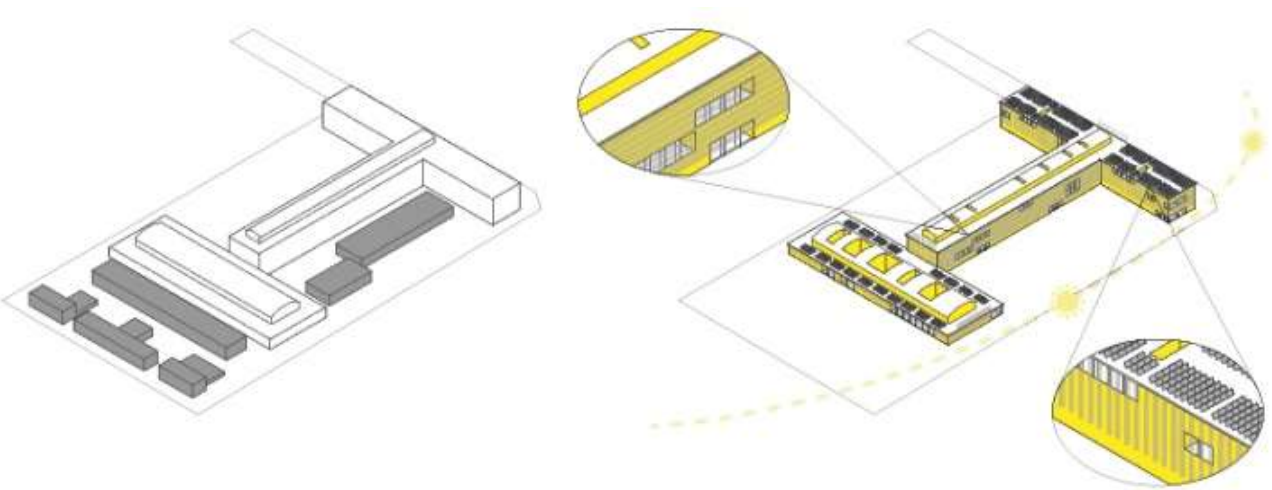

Figure 6. Conceptual Diagrams of the Project Development Scenarios that Verify the Mixed Scenario of the Industrial Hub and the Cold Chain Logistics Center. On the Left, the Planned Demolitions (in Grey) and on the Right, the Study of the Facade Enclosing and of the Shading

Source: Elaboration by Matteo Savron.

\section{Discussion}

The four strategic areas individuated, and the scenarios developed have been evaluated compared to the interests of the subjects involved, to the applicability of the methodology through scenarios and to the main themes of the study: innovation and infrastructure.

The area of the Prosecco station has a logistic and infrastructural freight village interest value for the municipality (Comune), Port Autority and the importexport operators.

It has the advantage of being able to become operative in a short period of time, but it did not seem to have any innovation potential in the research and development perspective, and so, for the purpose of the study it has not been considered meaningful.

Porto Vecchio attracts the interests of the municipality (Comune) and of the University of Trieste. The area measures $600 \mathrm{~m}^{2}$ and so an overall strategic planning is necessary, and it cannot be developed by single private operators.

It is an actual part of the city with respect to which the methodology through scenarios, probably, can be more efficiently utilized only at a later stage, after the definition of some infrastructural invariant on the urban scale, as at the moment in this vast area "everything is possible.",

The possibility to work on an area with such urban value can definitely allow to develop a resilient and circular strategy, in order to minimize or limit its environmental impact, as the new neighborhood is about $15 \%$ of the current historical center.

The maintenance strategy for the elaboration of such large area, would better benefit by the consideration of the model of Hamburg Hafencity, rather than utilize the scenario methodology. In this case the private operators propose to the

21. Fraziano, Trieste, la Misura del Possibile, 2014. 
public single projects for limited areas that only later are coordinated together with the programs and the more detailed designs. This is the more interesting stage as the propriety of the areas passes to the private promoters only after the obtainment of the building licenses necessary for the realization of the projects. ${ }^{22}$

This way the local administration can maintain a strong negotiating capability until the end of the process, while the private promoter economically exposes itself with the purchase of the areas only after having the certainty that its project has all the necessary paperwork to start the construction.

This is a development by parts process that in Hamburg is achieving success and it is necessarily developed around a time period of 20-30 years. With its long term vision, this strategy, also allows to manage unpredictable factors and remodulate the choices already made in order to answer to unfavorable circumstances.

The Campo Marzio field currently attracts the interests only of the importexport operators, as the other subjects seemed to be more interested in Porto Vecchio, an area with similar characteristics, but with larger extension and greater potential. In the recent past however, the area has been subject to different development hypothesis, one in particular regarding "Parco del Mare" (Sea Park), in the configuration studied by University of Trieste for Camera di Commercio (Chamber of Commerce) in 2007.

The project was set up to develop a marine aquarium, museum and congress spaces, with commercial areas and supporting accommodation facilities. The location seemed strategic from the infrastructural point of view as it is close to the so-called Grande Viabilità Triestine GVT (Great Viability of Trieste), the primary highway access to the city. On the Rive (boardwalk) the Stazione Marittima (marine station) is located and it is used as a cruise ship terminal, besides being the public marine transport station. Correlated to the structure of Parco del Mare, two other innovation structures were also foreseen: 1'Esposizione di Ricerca Avanzata (ERA) and the research center Sealab.

The Canale navigabile area, as anticipated, has been found as interesting by almost all of the subjects involved. The planned hypothesis was based on the logistic and infrastructural enhancement, regeneration and valorization of the industrial complexes in disuse by implementing new practices and development of production areas in FTZ (foreign trade zone) regime.

The visions of progress indicated are heterogenous and divergent among each other, for this reason the development through scenarios has resulted as efficient, as it has allowed to evaluate the different options from the strengths and weaknesses of each and define another intermediate synthetic scenario.

The cold chain logistics center is a greatly interesting scenario in terms of development of the area as it is easy to implement, from a technical-design point of view, as it only needs to reactivate an already existing logistics system and the realization of automated warehouses. The impact in terms of users and urban load is minimal but the innovative added value is limited. The intervention valorizes the

22. D. Polkowski, "'HafenCity Hamburg" The vision becomes reality," in European Green Capitals. Experiences of Sustainable Urban Regeneration (eds.) G. Capocchin, M. Botti, G. Furlan, S. Lironi. Siracusa: Lettera Ventidue, 2017. 
equipment of the already present infrastructure and utilizes the position of Trieste along the intercontinental commercial lines that go through the Suez Canal.

A specific theme of this scenario is robotization, one of the drivers of the 4.0 industry and the so-called "digital disruption." 23 The examples of automated logistics and the progressive marginalization of human workers are a reality of the big operators on the global scale that are progressively making the storage and distribution processes autonomous. ${ }^{24}$

The industrial hub is also considered a progress scenario, the high research and development content of this hypothesis brings however, the presence of other users that could overload the area that needs to be monitored. The applied research can valorize the productive and industrial activities currently present in the area, along with the future ones, and as a consequence, the infrastructural system already present is to be reactivated. The activity is also integrated with the larger system of research and development of the city of Trieste, enhancing it.

The production aspects linked to this scenario convey the theme of circular economy and of management of process residues. The development of an industrial district based on circular principles, such as improvement as a whole of the use of resources, offers strategic advantages linked to minor costs for energy supply, for optimization of the production chains and for waste disposal and reuse.

The Data Center turns out to be the most extreme scenario, the urban load on the area is minimal, the activity seems to be of high innovative content and is the cornerstone of a new digital infrastructural system, ${ }^{25}$ destined to manage the logistics of the Port that would have an avant-garde service, enhancing the role of Trieste as an intermodal hub of the naval routes arriving form the Suez Canal and the infrastructural European railway courses.

More than others, this scenario underlines characteristic themes of the IV industrial revolution, provision of services and management of Big Data. These are strategic areas and from these elements a new model of port can emerge, not a physical infrastructure anymore but as an agglomeration of services.

The first two scenarios, as indicated, have been used to create a new intermediate hypothesis that synthesizes in one solution most of the development proposals (Figure 7). The third scenario on the other side, has been considered incompatible with the first two. However, it does not have to be discarded as it offers an easy and quick implementation as an alternative solution.

23. C. Ratti (ed.), Building(in) the Digital Age. Construction \& Design 4.0 (Torino: Carlo Ratti Associati, 2019).

24. J. Le Cavalier, "Human Exclusion Zone. Logistics and New Machine Landscapes," Architectural Design 89, no. 1 (2019): 48-55.

25. L. Young, “Architecture without People. Neo-Machine,” Architectural Design 257 (2019): 6-13. 


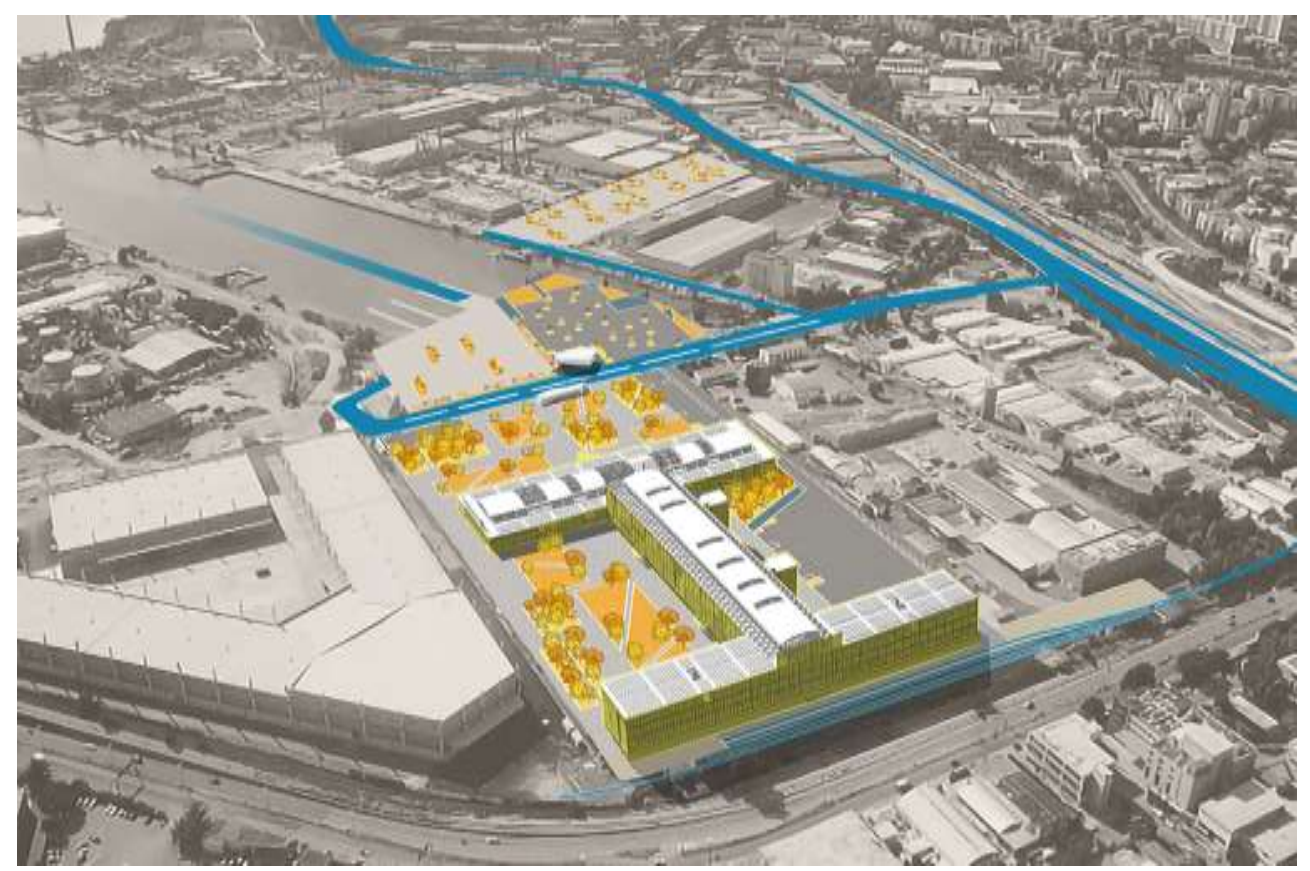

Figure 7. General Vision of the Architectural Intervention and of the Arrangement of the External Spaces and Connections with the Surrounding Infrastructural Systems

Source: Elaboration by Matteo Savron.

\section{Conclusions}

The application of the scenarios methodology in a precise location and with declared objectives is necessary for clear operative reasons. However, in these final considerations it is necessary to overcome the specificities of the case study in order to individualize more open and general principles, useful for the application of the same methodology in other contexts and in order to unfold further research disciplinary fields.

Using the scenario as a means for design allows to obtain high maintenance flexibility for the project that is able to answer to diverse initial suppositions or to intervening mutations of context. Simulation scenario methodologies demonstrate the capability to develop adaptable solutions to varied hypothesis and situations.

An example is the mutation of context following the diffusion of Covid-19 and the crisis that has followed. The production and supply systems are being reconfigured from a global scale to regional dimensions in order to maintain adequate levels of autonomy and self-sufficiency. In this picture, the image of a world order based on regional terminals in relation to one another, is reinforced.

At the same time infrastructures and digital services, thanks to their immaterial dimension, result as less exposed to the problem and to the restructuring of the logistics as they seem destined to maintain their global dimension. ${ }^{26}$

26. A. Lombardi, Lo Studioso Parag Khanna: Dopo il Virus Nascerà una Globalizzazione Regionale (La Repubblica, 2020). 
This study confirms the inversion of the hierarchy of the developed hypothesis, with a stronger proposal for the datacenter of the port, at the disadvantage of the industrial and logistics hub.

This global multipolar asset describes a dynamic picture where the two main hypothesis and methodologic choices remain valid: development of long term perspectives and infrastructural investments. As a consequence, creativity, innovation and engineering become strategic development areas, that allow some realities to become more competitive than others attracting new population and stimulating new forms of migration. ${ }^{27}$

In this case, one cannot only deduct these methodologic general conclusions; this study begins to outline some emerging architectonic typological questions, ${ }^{28}$ linked to the evolution of new landscapes in between infrastructure and innovation. The analysis of the scenarios and of the compatible activities with the interests of the promoting subjects of the investments, as a result, recognizes a series of actions and spaces with respect to which mankind seems to be progressively emarginated or absent. A new landscape made up of and for our machines, where infrastructure and storage spaces, both physical and digital, minimize the presence of the human user, that becomes occasional and accessory. ${ }^{29}$

In any case, these are empty spaces but still strategic, indispensable, in order to guarantee the functioning of the cities we live in; these are places that define the identity of the contemporary western culture but at the same time, we can never access them. A system, in many cases thought out for us but whose form, materiality and function are configured to answer to the logics of the new artificial living, where we are nothing more than intruders in an architecture that is completely indifferent to our presence and is leaving us behind.

\section{Acknowledgments}

Our thanks to: Research and didactic unit: Integrated Design and Architecture Laboratory, Department of Engineering and Architecture, University of Trieste (IT). Coordinator and scientific manager: Giovanni Fraziano (DIA - UNITS). Team of researchers: Adriano Venudo, Thomas Bisiani, Claudio Meninno, Luigi Di Dato, Marko Verri, Stefano Simionato (DIA - UNITS). Graduates in 2020 who have collaborated on the research team: Matteo Savron, author of the thesis "Trieste: nuovi scenari per uno sviluppo tra infrastruttura e innovazione" and Vittoria Umani translator and reviewer.

27. D. Taino, Ne usciremo tripolari: Occidente, Cina, Asia (Corriere della Sera, 2020).

28. R. Koolhaas, TRIC: Post-Human Architecture, in Countryside: A Report (ed.) K. R. Amo. Koln: Taschen, 2020.

29. Young, “Architecture without People. Neo-Machine,” 2019. 


\section{References}

Bellicini, L. and F. Toso. Un Nuovo Paradigma Urbano: "La Città è la Soluzione non il Problema." (A new Urban Paradigm: The City is the Solution not the Problem). CRESME. Il Mercato delle Costruzioni (2018): 8-13-8 - 14.

Bisiani, T., G. Fraziano, C. Meninno and A. Venudo. "Il Nuovo Polo Intermodale del Trieste Airport." (The New Intermodal Hub of Trieste Airport). Studi Goriziani 113 (2020): 113-129.

Burdett, R. and D. Sudjic. Living in the Endless City. London: Phaidon Press, 2011.

Burdett, R. and P. Rode. Shaping City. London: Phaidon Press, 2018.

Cairncross, F. The Death of Distance. How the Communications Revolution will Change our Lives. Cambridge: Harvard Business Press, 1997.

Carta, M. Re_Cyclical Urbanism. Visioni, Paradigmi e Progetti per la Metamorfosi Circolare. (Re_Cyclical Urbanism. Visions, Paradigms and Projects for Circular Metamorphosis). Trento: Listlab, 2016.

Carta, M. Augmented City. A Paradigm Shift. Trento: Listlab, 2017.

Castell, M. The Rise of the Network Society. Cambridge: Blackwell, 1996.

Dolezel, L. Heterocosmica. Fiction and Possible Words. Baltimore: Johns Hopkins University Press, 1998.

Dunne, A. and F. Raby. Speculative Everything. Design, Fiction, and Social Dreaming. Cambridge: MIT Press, 2013.

Ferrari, M. "Reti e Nodi Contemporanei, le Architetture delle Infrastrutture." (Contemporary Nets and Knots, Architecture of Infrastructure). In L'Architettura del Mondo. Infrastrutture, Mobilità, Nuovi Paesaggi. Edited by A. Ferlenga, M. Biraghi and B. Albrecht. Bologna: Editrice Compositori, 2012.

Fraziano, G. Trieste, la Misura del Possibile. (Trieste, Measuring the Impossible). Trieste: Fresco Editore, 2014.

Fraziano, G., T. Bisiani, L. Di Dato, C. Meninno, A. Venudo and M. Verri. Le Regole del Gioco. Scenari Architettonici e Infrastrutturali per l'aeroporto FVG. (The Rules of the Game. Architecture and Infrastructural scenarios for the FVG Airport). Trieste: EUT Edizioni Università d Trieste, 2015.

Khanna, P. Connectography. Mapping the Future of Global Civilization. New York: Random House, 2016.

Koolhaas, R. TRIC: Post-Human Architecture, in Countryside: A Report. Edited by K. R. Amo. Koln: Taschen, 2020.

Le Cavalier, J. "Human Exclusion Zone. Logistics and New Machine Landscapes." Architectural Design 89, no. 1 (2019): 48-55.

Lombardi, A. Lo Studioso Parag Khanna: Dopo il Virus Nascerà una Globalizzazione Regionale. (The Scholar Parag Khanna: After the Virus a New Regional Globalization will be Born). La Repubblica, 2020.

McLuhan, M. and G. E. Stearn (eds.) McLuhan. Hot and Cool. A Primer for the Understanding of and a Critical Symposium with Responses by McLuhan. New York: Dial Press, 1967.

Paffumi, S. "Il Secolo Asiatico e la Nuova via della Seta." (The Asian Century and the New Silk Road). Icon 54 (2019): 52-56.

Polkowski, D. ""HafenCity Hamburg" The vision becomes reality". In European Green Capitals. Experiences of Sustainable Urban Regeneration. Edited by G. Capocchin, M. Botti, G. Furlan, S. Lironi. Siracusa: Lettera Ventidue, 2017.

Ratti, C. (ed.) Building(in) the Digital Age. Construction \& Design 4.0. Torino: Carlo Ratti Associati, 2019. 
Ratti, C. and M. Claudel. La città di domani. Come le Reti Stanno Cambiando il Futuro Urbano. (The City of Tomorrow. How Networks are Changing the Urban Future). Torino: Einaudi, 2017.

Savron, M. Trieste: Nuovi Scenari per uno Sviluppo tra Infrastruttura e Innovazione. (New Scenarios for Development between Infrastructure and Innovation). Unpublished Thesis. Trieste: Università degli Studi di Trieste, 2020.

Secchi, B. Diario 06. Scenari. Planum, 2002.

Taino, D. Ne usciremo tripolari: Occidente, Cina, Asia. (We will Come out Tripolar: the West, China, Asia). Corriere della Sera, 2020.

Young, L. "Architecture without People. Neo-Machine." Architectural Design 257 (2019): 6-13. 
